\title{
Polluted Air Increases Perceived Corruption
}

\author{
Zhenwei Huang, Wenwen Zheng, Xuyun Tan, Xiaoxiao Zhang, and Li Liu \\ Beijing Key Lab of Applied Experimental Psychology, School of Psychology, Beijing Normal University, Beijing, China
}

\begin{abstract}
$\mathrm{D}$ rawing upon the moral cleanness metaphor and the power height metaphor, we proposed the clear sky effect: polluted air increases perceived corruption. To test the effect, we established a correlation (Studies 1 and 2) and causal link (Studies 3, 4, and 5) between haze pollution and corruption perception. This correlation is unique, in that, of various air pollutants, only the major haze indicator was positively correlated with corruption perception at city (Study 1) and country (Study 2) levels. In addition, recalling feelings concerning haze (Studies 3 and 5) or experiencing hazy days (Study 4) increased corruption perception. Furthermore, in support of embodiment, this effect was moderated by body awareness (Study 4) and mediated by bodily stress responses (Study 5). Taken together, these findings suggest that environmental pollution could be one of the factors that influence our trust in government.
\end{abstract}

Keywords: corruption perception, embodied cognition, haze, body consciousness

Perceived corruption is one of the most pressing societal problems, undermining political trust (Morris \& Klesner, 2010), reducing foreign investment (Arndt \& Oman, 2006), and stimulating corruptive behaviour (Č́belková \& Hanousek, 2004; Dong, Dulleck, \& Torgler, 2012). Recent research has identified a number of important antecedents for perceived corruption. These antecedents include both individual factors such as age (McCann \& Holt, 2009), socioeconomic status (Charron, 2015; Olken, 2009) and lay beliefs (Bai, Liu, \& Kou, 2014; Tan, Liu, Huang, Zhao, \& Zheng, 2016), and institutional factors such as GDP (Ata \& Arvas, 2011), decentralisation (Fisman \& Gatti, 2002; Lessmann \& Markwardt, 2010) and collectivism (Davis \& Ruhe, 2003; Mazar \& Aggarwal, 2011; Seleim \& Bontis, 2009). However, the role of environmental factors on perceived corruption has previously been overlooked. Inspired by research on embodied cognition (e.g, Huang, 2014; Schnall, Benton, \& Harvey, 2008; Zhong \& Liljenquist, 2006), we postulated that polluted air increases perceived corruption.

We tested this clear sky effect, which is compatible with the canon of embodiment, especially the moral cleanness metaphor and the power height metaphor. On one hand, the moral-cleanness metaphor links physical and moral cleanliness. A growing body of studies has demonstrated that morality is related to cleanliness (Huang, 2014; Lee \& Schwarz, 2010, 2011; Schnall et al., 2008; Zhong \& Liljenquist, 2006), and immorality is considered dark (Meier, Robinson, \& Clore, 2004; Sherman \& Clore, 2009). Similarly, corruption is linguistically linked to dirtiness (Nui- jten, 2004; Olson \& Carroll, 1992), darkness (Aguilera \& Vadera, 2008), and a lack of transparency (Transparency International, 2013).

On the other hand, sky is the metaphor for height and the symbol of power. Previous research has demonstrated that evaluations of a power can be increased by information about high vertical positioning in space (Giessner \& Schubert, 2007; Schubert, 2005). Thinking about the abstract concept of power may automatically activate the spatial up-down image schema (powerful up; powerless down; Zanolie et al., 2012). Furthermore, this power height metaphor is also supported by evidence from language. In the West, the powerful are addressed as 'your highness'. In Chinese history, an emperor was regarded as the Son of Heaven (天子). Given that officials and government represent power, they are linked to the sky above.

Embodied theory and relevant empirical research suggest that dirtiness, darkness, and opacity are connected with corruption, and the sky is connected with government. Haze is perceived to darken the sky and defile the atmosphere. In particular, the major indexes of haze, dust, and smoke particles obscure the clarity of the sky (Barker, 1976; Bickerstaff \& Gordon, 2001; Hyslop, 2009). Therefore, haze, corruption, and government are interrelated. However, the gaseous pollutants, such as sulfur dioxide $\left(\mathrm{SO}_{2}\right)$ and nitrogen oxides (NO), are not easily perceived (Barker, 1976). Taken together, evidence from embodiment implies that haze alone could increase the perception of government corruption (Hypothesis 1). 
It has been demonstrated that the embodiment effect can be amplified by body consciousness (Schnall, Haidt, Clore, \& Jordan, 2008). Bodily consciousness refers to the ability to detect subtle changes in bodily systems, including muscles, skin, joints, and viscera (Miller, Murphy, \& Buss, 1981). If embodiment played a role in the association between haze and perceived corruption, we could expect that participants with higher bodily consciousness would be more likely to perceive an increase in corruption when they perceive physical pollution (hypothesis 2).

Haze is perceived in an embodied manner. In particular, haze elicits bodily stress responses (Bickerstaff \& Gordon, 2001; Hyslop, 2009), including respiratory symptoms (Dockery \& Pope, 1994), asthma and allergy (Brauer et al., 2007). Recent psychological research on embodiment reveals that visceral states influence psychological processes (Barsalou, 2008; Niedenthal, Barsalou, Winkielman, Krauth-Gruber, \& Ric, 2005; Risen \& Critcher, 2011). Therefore, based on embodiment, we could expect that bodily responses act as the mediator variable in the relationship between haze and corruption perception (hypothesis 3 ).

To examine these hypotheses, we employed multiple methods, including archival analyses and experiments, in this research. Archival analyses investigated the relationship between haze and corruption perception at city and country levels. These correlational analyses were further coupled with experiments at the individual level to allow causal claims. We thereby determined whether and how haze accounted for changes in corruption perception. More specifically, we explored the relationship between haze and corruption perception in five studies. Studies 1 , 2 , and 3 aimed to explore the relationship between haze and corruption perception (Hypothesis 1). In Studies 1 and 2, we examined the correlations between various air pollutants and their concentration (i.e., particulates and gaseous pollutants) and corruption perception at city and country levels, respectively. In Study 3, we sought to extend the correlational results reported in Studies 1 and 2 by manipulating perceived haze and measuring corruption perception at an individual level. Studies 4 and 5 sought to further identify the moderator and mediator that can be interpreted as providing empirical support for embodiment.

\section{STUDY 1: CITY-LEVEL ANALYSIS}

Studies 1 and 2 explored the association between air pollution and perceived corruption by using archive data. We expected various air pollutants to be related to corruption perception if environmental degradation was fuelled by corruption. However, we expected only perceivable air pollutants to be related to corruption perception if corruption perception was related to environmental degradation resulting from embodied cognition.

To control the effects of cultural and political factors on corruption perception, the data from Study 1 were col- lected at a city level within a single country (China). We used archival data concerning actual air pollutant emissions. Haze often occurs when dust and smoke particles accumulate in relatively dry air; therefore, concentrations of dust and smoke particles, rather than $\mathrm{SO}_{2}$ or $\mathrm{NO}$ (a mixture of a binary compound of oxygen and nitrogen) emissions, are major indicators of haze.

\section{Method}

Data regarding corruption, economy, and air pollution were drawn entirely from published sources. Crosssectional analysis was performed using two independent data sets: (1) the 2011 Corruption Perceptions Index scores from 36 major Chinese cities (Song \& Cheng, 2012), which were recoded so that higher scores means higher levels of corruption perception; and (2) each region's 2011 per capita gross domestic product and air pollutants, including dust and smoke particles and $\mathrm{SO}_{2}$ and $\mathrm{NO}$ emissions, from the National Bureau of Statistics of China Database (data.stats.gov.cn/workspace/index? $\mathrm{m}=$ fsnd).

\section{Results and Discussion}

We performed general linear model analysis to examine the association between air pollution and perceived corruption. We standardised all variables for ease of comparison. With the economy controlled for, $\mathrm{SO}_{2}(p=.36)$ and NO $(p=.18)$ emissions were not related to corruption perception. In contrast, dust and smoke-particle concentration were positively associated with corruption perception, $\beta=.55, t(31)=2.34, p<.05$, semipartial $r=.387$.

A unique connection between particles and corruption perception was indicated by the finding that $\mathrm{SO}_{2}$ and $\mathrm{NO}$ did not exert similar effects. These findings refuted the economic viewpoint that all air pollutants $\left(\mathrm{SO}_{2}, \mathrm{~N}_{2} \mathrm{O}\right.$, and dust and smoke particles) are associated with corruption perception (Cole, 2007; Welsch, 2004). In contrast, the findings indicated that only air pollution involved in physical perception - haze - was associated with corruption perception. This supported our explanation of the association between air pollution and corruption perception.

\section{STUDY 2: COUNTRY-LEVEL ANALYSIS}

Although Study 1 yielded an initial evidence for a unique relationship between haze and perceived corruption, the results were limited to China during 2011. Study 2 sought to replicate the unique relationship between haze and corruption across time at a country level. We analysed longitudinal data from 56 countries in a two-level linear growth model (within countries over a 7-year period). As dust and smoke particles were the major sources of haze, concentrations of particulate matter of less than 10 microns in diameter (PM10), rather than emissions of of nitrous oxide $\left(\mathrm{N}_{2} \mathrm{O}\right)$, carbon dioxide $\left(\mathrm{CO}_{2}\right)$ or other greenhouse gases, were considered major indicators of haze. 
In this study, we controlled for the economy, culture, and government size because these variables have all been linked to corruption perception in cross-national analyses (e.g., Cole, 2007; Davis \& Ruhe, 2003; Welsch, 2004).

\section{Method}

Data concerning corruption, air pollution, economy, and culture were drawn entirely from published sources. We used the following three independent data to perform a cross-national analysis: (1) the 2004-2010 Corruption Perceptions Index developed by Transparency International (www.transparency.org/research/cpi/), which were recoded so that higher scores means higher levels of corruption perception; (2) the 2004-2010 per capita gross domestic product, and government size and air pollution indicators including PM10 concentrations, $\mathrm{N}_{2} \mathrm{O}, \mathrm{CO}_{2}$, and other greenhouse gas emissions at a country level, from the World Bank (data.worldbank.org/indicator); and (3) culture scores, including power distance, individualism, masculinity, and uncertainty avoidance, from the Values Survey Module (www.geerthofstede.nl/vsm2013).

\section{Results and Discussion}

To determine whether greater amounts of air pollution were associated with higher corruption perception within countries over time, we ran several linear growth models in hierarchical linear modeling (HLM) with fixed effects. This approach is preferable to standard regression because each country's consumer price index (CPI) was measured over several years, which resulted in two levels of error variance (country and year), and HLM is able to separate these (Snijders \& Bosker, 1999). Understanding how the total variance was partitioned across the levels provides insight into the degree to which year-level variance of air pollution (Level 1) and country-level variance of air pollution (Level 2) influenced the year-to-year CPI. In our analysis, years were nested within countries. We standardised all variables for ease of comparison. Masculinity and uncertainty avoidance were not significant predictors of high corruption perception ( $p s>.75$ ); therefore, they were not included in all of the models.

Table 1 shows the results of this analysis. Within countries, haze (PM10 concentration) was a significant predictor of differences in perceived corruption over time, $t(417)$ $=3.23, p<.01$, while $\mathrm{N}_{2} \mathrm{O}(p=.38), \mathrm{CO}_{2}(p=.23)$, and other greenhouse gases $(p=.14)$ were not.

We used a multilevel framework to determine whether air pollution accounted for changes in perceived corruption while controlling for economic and cultural factors. Within countries, haze pollution positively predicted perceived corruption, while $\mathrm{N}_{2} \mathrm{O}$ and $\mathrm{CO}_{2}$ pollution did not. Again, our findings refuted the notion that corruption generally increases environmental pollution (Damania et al., 2003). Instead, they supported the embodied view that only visible pollution, haze, is correlated with corruption perception.

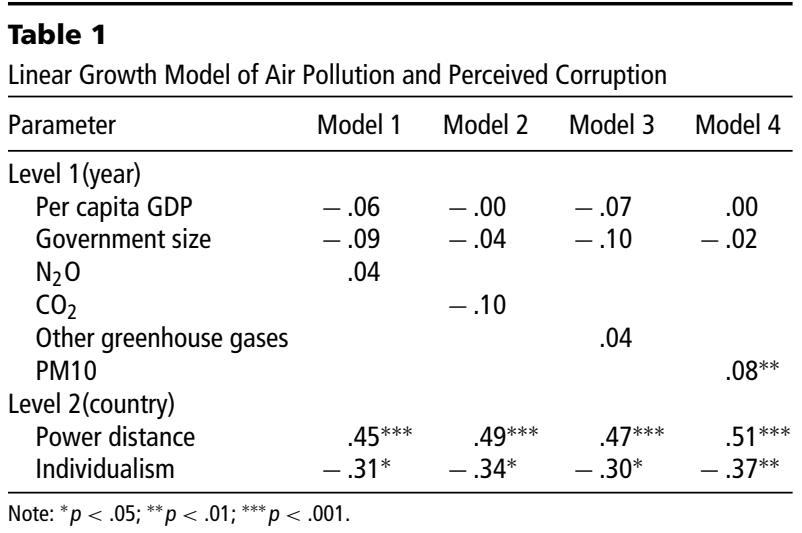

\section{STUDY 3: THE EFFECT OF HAZE ON CORRUPTION PERCEPTION}

Although Studies 1 and 2 yielded evidence of an embodied cognition explanation of the relationship between haze and corruption perception, the results were obtained at a group level. To determine whether the relationship between these two constructs existed at an individual level, we conducted Studies 3, 4 and 5. In Study 3, we sought to determine whether priming participants' feelings concerning haze would cause them to perceive the government as corrupt.

Studies 3, 4 and 5 were performed in accordance with the Declaration of Helsinki on Biomedical Research Involving Human Subjects. The protocols were approved by the Ethics Review Committee at the School of Psychology, Beijing Normal University. All participants provided informed consent, and were free to withdraw from the study at any time.

\section{Method}

\section{Participants}

Fifty-two individuals (26 males) between the age of 18 and $34\left(M_{\mathrm{age}}=21.8, S D_{\mathrm{age}}=2.90\right.$ years $)$ participated in the experiment. Participants were randomly assigned to the haze $(n=26)$ or neutral condition $(n=26)$ in a between-participants design.

\section{Materials}

Haze manipulation. To activate feelings concerning haze, participants in the haze condition were instructed to recall a time during which it had been hazy and record the feelings they had experienced at the time, in writing. Participants in the neutral condition did not receive this instruction.

Perceived corruption. The overall perception of unethical behaviours was measured using the Ruch and Newstrom (1975) Ethics Scale, in which participants rated the extent to which 17 behaviours observed in the country's civil servants are unethical. Responses were provided using a 


\begin{tabular}{|c|c|c|c|c|c|c|c|c|c|c|c|}
\hline Date & 3.28 & 3.29 & 3.30 & 3.31 & 4.1 & 4.2 & 4.3 & 4.4 & 4.5 & 4.6 & 4.7 \\
\hline$\overline{A Q I}$ & 162 & 55 & 88 & 181 & 161 & 135 & 57 & 79 & 66 & 92 & 134 \\
\hline Condition & Hazy & Clear & Clear & Hazy & Hazy & $-^{a}$ & Clear & $-^{a}$ & Clear & $-^{a}$ & hazy \\
\hline
\end{tabular}

Note: AQI fluctuated up and down 100. It is not appropriate to classify these days to hazy or clear day.

7-point Likert-type scale ranging from 1 (none of them) to 7 (all of them). The scale contains six corruption items, including two pertaining to bribery (e.g., accepting gifts/favours in exchange for preferential treatment) and four pertaining to embezzlement (e.g., using organisational services for personal use). Cronbach's $\alpha$ s in the current sample were .93 for the overall scale and .89 for the six corruption items.

\section{Procedure}

Participants were informed that the survey consisted of several independent studies with different goals. Aside from the inclusion or exclusion of the instruction to recall feelings experienced on a hazy day, as described above, the survey was identical in both conditions and consisted of the Ethical Perception Scale, demographic questions, and a suspicion check. The participants then received a gift and underwent funnel debriefing.

\section{Results and Discussion}

We performed several one-way ANOVAs to examine the effect of priming (haze condition vs. neutral condition) on the perception of corruption and unethical behaviour. The results showed a significant effect of haze priming on the perception of corruption (bribery and embezzlement), $F(1,50)=12.11, p<.01, \eta^{2}=.20$. Participants in the haze condition perceived a higher level of corruption $(M=5.41, S D=0.23)$ relative to that perceived by those in the neutral condition $(M=4.40, S D=0.15)$. The results also revealed a significant effect of haze priming on the perception of unethical behaviour, $F(1,50)=12.04$, $p<.01, \eta^{2}=.19$. Participants in the haze condition perceived a higher level of unethical behaviour $(M=5.00, S D$ $=0.16)$ relative to that perceived by those in the neutral condition $(M=4.17, S D=0.18)$.

The results of Study 3 confirmed and extended the findings of previous studies by demonstrating a causal effect of haze priming on corruption perception. The findings also indicated that inducing feelings regarding haze increased overall perception of unethical behaviour, suggesting that the effect of haze priming was not limited to the perception of corruption and applied to that of various immoral conducts. This is consistent with the moral cleanness metaphor (Barsalou, 2008; Landau, Meier, \& Keefer, 2010).

\section{STUDY 4: THE MODERATING ROLE OF BODY CONSCIOUSNESS IN THE LINK BETWEEN ACTUAL HAZE AND PERCEIVED CORRUPTION}

In Study 4, we sought to determine whether the embodiment effect could explain the link between haze and perceived corruption (Hypothesis 2). In addition, Study 3 used an experimental haze manipulation; therefore, to improve the ecological validity of the findings, it was important to replicate the results using actual hazy weather.

\section{Method}

\section{Participants}

One hundred and four individuals (50 males) between the age of 17 and 26 ( $M_{\text {age }}=21.3, S D_{\text {age }}=2.03$ years $)$ participated in the experiment. Three participants guessed the experimental purpose and two did not follow the instructions, leaving 49 and 50 participants in the hazy and clear weather conditions, respectively.

\section{Materials}

Haze manipulation. The experiments were conducted from March 28 to April 7, 2014. During these 11 days, there were no news events involving corruption, and the weather alternated between hazy and clear (see Table 2). Particle pollution data were collected at multiple points in Beijing and updated in real time, allowing us to maintain awareness of the latest haze situation. We did not conduct experiments on April 2, 4, and 6 because of the changeability of the pollution situation on these days. We recruited 13 participants on each of the remaining 8 days. Among 104 participants, every 13 shared the same haze situation. In other words, we had eight levels of haze, which is not enough for analysis. Therefore, in search of the effect of haze, we categorised the weather as either hazy or clear according to data published on China's National Air Quality Monitor Net (http://www.cnpm25.cn/city/beijing.html). When the air quality index (AQI) for particle pollution was below 100 according to the standards for pollution (U.S. Environmental Protection Agency, 2014), we classified the weather as clear. When the air quality index for particle pollution was above 100, we classified the weather as hazy. There were four hazy days (March 28 and 31, and April 1 and 7) and four clear days (March 29 and 30, and April 3 and 5).

We recruited 13 participants per day to control individual differences. We categorised the weather as either hazy or clear according to data published on China's National 
Air Quality Monitor Net (http://www.cnpm25.cn/city/ beijing.html).

Manipulation check. Participants rated their feelings concerning haze by answering the following questions, using 7-point Likert scales: (a) 'What is the color of the sky today?' Responses ranged from 1 (blue) to 7 (gray); (b) 'How hazy is it today?' Responses ranged from 1 (not at all) to 7 (extremely hazy); and (c) 'How necessary is it to wear a mask today?' Responses ranged from 1 (not at all) to 7 (extremely necessary).

Perceived corruption. A questionnaire adapted from the corruption perception measure developed by Transparency International (2013) was used to assess perceived corruption. The questionnaire included 14 key questions concerning local residents' perceptions of various aspects of urban corruption (e.g., officeholders can exploit their offices for private gain as they see fit without fear of legal consequences or adverse publicity). Cronbach's $\alpha$ in the current sample was .81.

Body consciousness. The Private Body Consciousness Questionnaire (Miller et al., 1981) was used to assess body consciousness and included five items (e.g., 'I am sensitive to internal bodily tensions'). Cronbach's $\alpha$ in the current sample was .72.

\section{Procedure}

Participants were approached on hazy or clear days. We recruited participants via face-to-face encounters in five teaching buildings at the same university in Beijing at one of four times (9:00-10:00 am, 12:00 am to 1:00 pm, 3:004:00 pm, and 6:00-7:00 pm). The timing of the surveys was matched between conditions. Men and women were selected in random order.

Participants were informed that the survey consisted of a number of independent studies with different goals. The survey was identical in both conditions and consisted of the Corruption Perception Scale, Body Consciousness Scale, a haze manipulation check, demographic questions, and a suspicion check. The participants then received a gift and underwent funnel debriefing.

\section{Results and Discussion}

Participants' feelings concerning haze were analysed using a two-way ANOVA with weather (hazy vs. clear) and body consciousness (low vs. high) as between-subjects factors. Participants reported significantly higher haze ratings on hazy days $(M=4.51, S D=0.18)$ relative to those reported on clear days $(M=2.00, S D=0.18), F(1,95)$ $=96.56, p<.001, \eta^{2}=.50$. Therefore, participants' responses agreed with actual haze data. The main effect of body consciousness and the haze $x$ body consciousness interaction on haze rating were non-significant ( $p s>.36$ ). Therefore, feelings concerning haze were not affected by body consciousness.

General linear model analysis was performed to examine the effect of haze on perceived corruption. For ease of

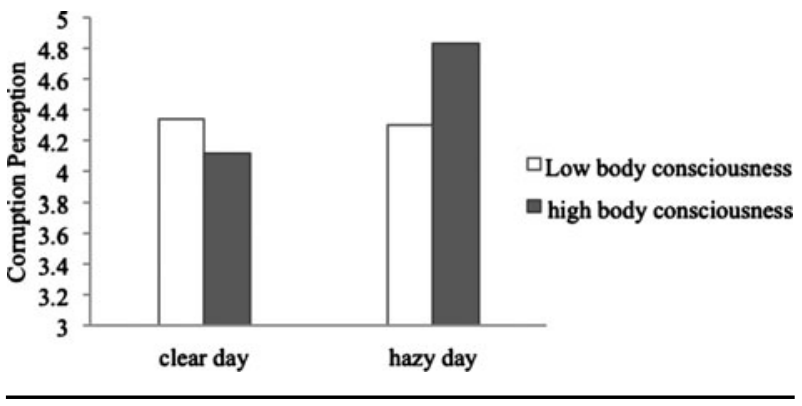

\section{Figure 1}

The effect of the interaction between haze and body consciousness on perceived corruption.

comparison, we standardised all of the variables. Corruption perception was then examined via multiple regression analysis involving weather (hazy $=1$, clear $=-1$ ) and body consciousness and their interaction. The main effect of body consciousness did not reach conventional levels of significance $(p=.07)$. The effect of hazy weather was significant $(B=0.17), t(95)=2.21, p<.05$. In addition, the haze $\times$ body consciousness interaction was significant $(B=0.26), t(95)=3.40, p<.01, \Delta R^{2}=0.10$.

To clarify the effects of body consciousness further, we employed the dichotomous score for body consciousness (used by Schnall et al., 2008) for moderation analysis. A two-way ANOVA was performed with weather (hazy vs. clear) and body consciousness (low vs. high) as betweensubjects factors. The main effect of body consciousness was non-significant $(p=.32)$. As predicted, the main effect of hazy weather was significant, $F(1,95)=4.75, p<.05, \eta^{2}$ $=.05$. Participants in the hazy weather condition perceived the government as more corrupt $\left(M_{\text {haze }}=4.55, S D_{\text {haze }}\right.$ $=0.81)$ relative to those in the clear weather condition $\left(M_{\text {not haze }}=4.23, S D_{\text {not haze }}=0.76\right)$. The haze $\times$ body consciousness interaction was also significant, $F(1,95)$ $=5.87, p<.05, \eta^{2}=.06$ (see Figure 1). For those with high levels of body consciousness, haze increased levels of perceived corruption, $F(1,95)=10.28, p<.01, \eta^{2}=.10$, $M_{\text {haze }}=4.83, S D_{\text {haze }}=0.15, M_{\text {not haze }}=4.12, S D_{\text {not haze }}$ $=0.18$. However, for those with low body consciousness, haze did not affect perceived corruption $(p=.86)$.

We replicated the causal effect of haze on the perception of corruption using an ecological haze manipulation. Participants in the hazy weather condition perceived the government as more corrupt relative to those in the clear weather condition. We also extended this finding via theoretically predicted embodiment: the association between haze and perceive corruption was limited to participants who were most likely to attend to their own visceral reactions. Participants with high levels of body consciousness in the hazy weather condition perceived the government as more corrupt relative to those in the clear condition, whereas participants with low body consciousness were not affected by hazy weather. The moderation data suggests that haze increased perceived corruption via an embodied process. 


\section{STUDY 5: THE MEDIATING ROLE OF BODILY STRESS RESPONSES}

In Study 5, we improved upon Studies 3 and 4 in two ways. First, Study 5 used a more rigourous manipulation of haze. In Study 3, perceived corruption in hazy conditions is compared with conditions in which no cue is presented. However, haze manipulation in pollution studies is similar to weather manipulations' metacognitive affect within information studies (Schwarz \& Clore, 1983). The question remains: Is haze different from bad weather? In order to redress this lacuna, we developed Study 5, in which perceived corruption in hazy conditions is compared with a condition in which feelings and/or remembrances of a cloudy day were elicited.

Second, Study 5 provided more solid evidence for embodiment by determining the mediating role of bodily stress responses (Hypothesis 3 ). It is possible that haze may increase negative affect, which drives judgments about corruption. This alternative would be consistent with an affect as an information theoretical position (Schwarz \& Clore, 1983). However, if an embodied process is occurring, it may be possible to find a psychological mediator affected by the physical pollution manipulations. In sum, the purpose of Study 5 was to rule out an affect as an information theoretical position, and to provide further support for an embodiment explanation.

\section{Method \\ Participants}

Forty-four participants ( $21 \mathrm{men} ; M_{\text {age }}=28.6$ years; $S D_{\text {age }}$ $=9.2$ years) voluntarily participated in this study. Participants were randomly assigned to one of two conditions: the haze condition $(n=23)$ or the control condition $(n=$ 21).

\section{Materials}

Haze manipulation. Participants in haze versus control condition received a form that instructed them to recall when it was hazy versus cloudy and to indicate the lighting quality on hazy versus cloudy days. The perceived lighting quality was assessed using 7-point Likert scales (Johansson, Pedersen, Maleetipwan-Mattsson, Kuhn, \& Laike, 2014). A total of six items were used. They were 'drab-clear', 'subdued-brilliant', 'dark-light', 'shaded-glaring', 'mild-sharp' and 'unfocused-focused'. Cronbach's $\alpha$ of the light quality scale in the current sample was .90 .

Consequentialist versus ethical emotions. The scale from Böhm (2003) was used to measure four types of emotion: prospective (hope, worry, fear, hopelessness) and retrospective (sadness, regret, sympathy) consequence-based emotions, and other-related (disgust, anger, outrage, contempt, disappointment) and self-related (guilt, shame) ethics-based emotions. Participants rated how intensely they felt each of these 14 specific emotions when it was hazy/cloudy on 7-point rating scales, ranging from 1 (not at all) to 7 (very much). Since these four measures were highly correlated within participants $(r s>.55$, all $p s<$ .01 ), we averaged the four types of emotion to create an overall measure negative emotion.

Bodily stress responses. The scale from Beck, Epstein, Brown, and Steer (1988) was used to measure bodily stress responses. A sample item was: 'I experienced trembling (e.g., in the hands).' Participants rated how intensely they experienced each bodily stress response on hazy days on 7-point rating scales, ranging from 1 (not at all) to 7 (very much). Cronbach's $\alpha$ in the current sample was .84 .

Corruption perception. We used a measure of corruption perception based on a prior trust scale (Craig, Niemi, \& Silver, 1990). A sample item was 'Unless we keep a close watch on them, many officers will look out for personal interests rather than for all the people. Two items in the original measure that did not seem suitable for our present purposes measured corruption perception. Thus, these two items were omitted. They are 'When government leaders make statements to the American people on television or in the newspapers, they are usually telling the truth' and 'Most of the people running our government are wellqualified to handle the problems that we are facing in this country'. Participants used 7-point Likert scales to enter their responses $(1=$ strongly disagree, $7=$ strongly agree $)$. Cronbach's $\alpha$ in the current sample was .76.

\section{Procedure}

Participants were told that they would finish two supposedly unrelated surveys: a haze-related survey and a social attitude survey. All materials were presented in a questionnaire. The questionnaire starts with the haze survey (including haze manipulation, the emotions and bodily stress responses) and is followed by the social attitude survey (corruption perception ratings). The final part of the questionnaire consists of questions concerning demographical information. None of the questions indicated the experiment's true purpose. The participants were then given a gift and a funnel debriefing.

\section{Results and Discussion}

\section{Main Effect of Haze}

Descriptive statistics and significance tests are presented in Table 3. As expected, participants' reported lighting quality varied by condition. In particular, reported levels of lighting quality were lower in the haze condition compared with the control condition. Haze priming increased three types of emotion (prospective-retrospective, consequence-based emotion and other ethics-based emotion), while it had no effect on self ethics-based emotion.

Also as predicted, participants reported greater corruption perception in the haze priming condition than in the control condition. We observed the same pattern of results for bodily stress responses: participants were more likely to experience bodily stress responses in the haze priming condition than in the control condition. 
Table 3

Means for Dependent Variables as a Function of Condition in Study 5

\begin{tabular}{|c|c|c|c|c|}
\hline \multirow[b]{2}{*}{ Dependent variable } & \multicolumn{2}{|c|}{ Condition } & \multirow[b]{2}{*}{$F(1,42)$} & \multirow[b]{2}{*}{$\eta^{2}$} \\
\hline & Haze & Control & & \\
\hline Light quality & 2.63 & 3.67 & $10.68^{* *}$ & 0.11 \\
\hline \multicolumn{5}{|l|}{ Emotion } \\
\hline $\begin{array}{l}\text { consequence-based, } \\
\text { prospective }\end{array}$ & $2.88(1.20)$ & $2.06(1.15)$ & $2.30^{*}$ & 0.11 \\
\hline $\begin{array}{l}\text { consequence-based, } \\
\text { retrospective }\end{array}$ & $3.00(1.27)$ & $2.25(1.01)$ & $4.51^{*}$ & 0.10 \\
\hline ethics-based, other & $3.51(1.65)$ & $1.81(1.18)$ & $15.34^{* * *}$ & 0.27 \\
\hline ethics-based, self & $2.09(1.24)$ & $1.62(1.05)$ & 1.80 & 0.04 \\
\hline $\begin{array}{l}\text { Mean (negative } \\
\text { emotion) }\end{array}$ & $2.87(1.16)$ & $1.93(0.93)$ & $8.54^{* *}$ & 0.17 \\
\hline Bodily stress response & $1.86(0.97)$ & $3.37(1.12)$ & $22.64^{* * *}$ & 0.35 \\
\hline Corruption perception & $4.25(1.17)$ & $5.06(0.92)$ & $6.53^{*}$ & 0.14 \\
\hline
\end{tabular}

\section{Table 4}

Correlations Among Emotions, Bodily Stress Responses and Perceived Corruption

\begin{tabular}{lllllll}
\hline & 2 & 3 & 4 & 5 & 6 & 7 \\
\hline $\begin{array}{l}\text { 1. Consequence-based, } \\
\text { prospective }\end{array}$ & $.84^{* *}$ & $.79^{* *}$ & $.58^{* *}$ & $.92^{* *}$ & $.46^{* *}$ & .28 \\
$\begin{array}{l}\text { 2. Consequence-based, } \\
\text { retrospective }\end{array}$ & $.67^{* *}$ & $.62^{* *}$ & $.89^{* *}$ & $.32^{*}$ & .09 \\
3. Ethics-based, other & & & & & \\
$\begin{array}{l}\text { 4. Ethics-based, self } \\
\text { 5. Negative emotion }\end{array}$ & & $.55^{* *}$ & $.89^{* *}$ & $.48^{* *}$ & $.33^{*}$ \\
$\begin{array}{l}\text { 6. Bodily stress } \\
\text { responses }\end{array}$ & & & $.77^{* *}$ & $.30^{*}$ & .19 \\
\begin{tabular}{l} 
7. Corruption perception \\
\hline Note: ${ }^{\dagger} p<.08,{ }^{*} p<.05,{ }^{* *} p<.01,{ }^{* * *} p<.001$.
\end{tabular} & & & $.46^{* *}$ & $.27^{\dagger}$ \\
\end{tabular}

Predicting Corruption Perception From Emotions and Bodily Stress Responses

Bivariate correlations among emotions, bodily stress responses, and corruption perception are reported in Table 4. As predicted, the increase in bodily stress responses was associated with the increase in corruption perception. Also as expected, bodily stress responses were significantly associated with each of the four types of emotion. Among the four types of emotion, only one was significant for corruption perception, other-related ethics-based emotion (e.g., anger). In addition, negative emotion was marginally significantly associated with corruption perception.

\section{Mediation Analyses}

Next, we conducted mediation analyses (Baron \& Kenny, 1986) to test whether bodily stress responses explained the relationship between the haze and increased corruption perception. As shown in Figure 2, the effect of haze prime was reduced to non-significance, from $B=0.36, t(42)$ $=2.17, p<.05$, to $B=0.07, t(41)=0.39, p=.70$, when bodily stress responses were included in the model; and greater bodily stress responses were associated with higher corruption perception, $B=0.38, t(41)=2.46, p<$
.05. A bootstrap analysis showed that the $95 \%$ confidence interval (CI) for the size of the indirect effect is $[0.03,0.54]$, excluded zero, which suggested a significant indirect effect (MacKinnon, Fairchild, \& Fritz, 2007).

We also included other ethics-based emotion as a potential mediator. This allowed us to test the alternative hypothesis that the effect of haze on corruption perception could be explained by negative emotions. Neither haze, $B=0.29$, $t(41)=1.59, p=.12$, nor other ethicsbased emotion, $B=0.13, t(41)=1.17, p=.25$, were associated with corruption perception in the multivariate model. Consequently, other ethics-based emotion was not a significant mediator, $95 \% \mathrm{CI}=[-0.03,0.27]$. Furthermore, controlling for these emotions, the mediating effect of bodily stress responses was still significant (Figure 3).

These results suggested that haze increased corruption perception through bodily stress responses. By measuring bodily stress responses caused by air pollution, Study 5 provided a stronger evidence for embodiment.

Although three types of emotions (prospective consequence-based emotion, retrospective consequencebased emotion, and other ethics-based emotion) were increased by haze, none of them mediated the link between haze and corruption perception. Furthermore, the mediating effect of bodily stress responses held when we controlled simultaneously for emotions.

\section{General Discussion}

The results of the five studies indicated that haze was associated with perceived corruption. At city (Study 1) and country (Study 2) levels, haze was positively correlated with perceived corruption, while other air pollutants were not. More importantly, at an individual level, participants reported higher levels of perceived corruption subsequent to recalling feelings concerning haze (Studies 3 and 5) or experiencing hazy days (Study 4). Furthermore, Studies 4 and 5 provided empirical support for embodiment as a mechanism linking haze and corruption. On the one hand, body consciousness - a personal trait known to encourage embodied cognition - amplified the relationship between haze and perceived corruption (Study 4). On the other hand, the effect of haze on corruption perception was mediated by bodily responses (Study 5). Therefore, embodied cognition was an important psychological process underlying the association between haze and perceived corruption.

Our results cast doubt on the widely accepted assumption that perceived corruption adequately reflects the reality of corruption (e.g., Song \& Cheng, 2012; Transparency International, 2013; Charron, 2015). In Study 3, half of the participants were asked to recall haze experiences, and the other half were not asked to recall anything. Our findings indicate that participants who recalled haze experiences reported higher levels of perceived corruption relative to that reported by those who did not recall anything. The findings of Study 3 indicated that the perception of haze 


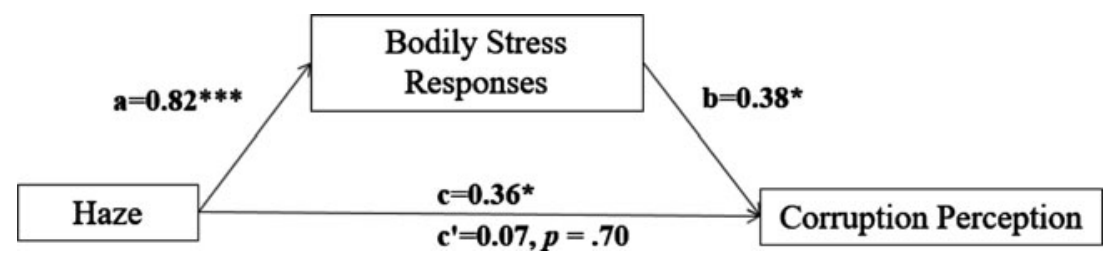

\section{Figure 2}

Testing the mediating role of bodily stress responses.

Note: ${ }^{*} p<.05 ;{ }^{* * *} p<.001$.

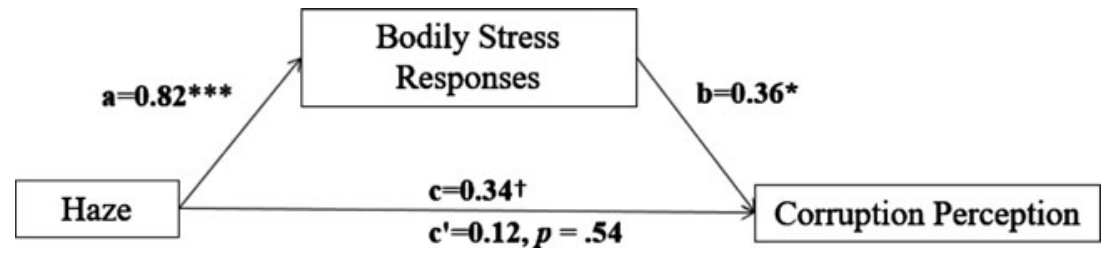

\section{Figure 3}

Testing the mediating effect of bodily stress responses while controlling negative emotions.

Note: ${ }^{\dagger} p<.06 ; * p<.05 ; * * * p<.001$.

increased levels of perceived corruption. In Study 4, during the 11 days when we recruited participants, there were no news events involving corruption, and the weather alternated between hazy and clear. Accordingly, the actual official corruption level should have been the same on the hazy and clear days on which we recruited participants. Further, we controlled the influence of personal extraneous variables by randomly recruiting participants on hazy and clear days. If perceived corruption reflected actual corruption levels accurately, participants in both weather conditions should have reported the same level of perceived corruption. However, our results showed that participants who experienced haze reported higher levels of perceived corruption relative to those who experienced clear air. Further, the effect was large in Study $3\left(\eta^{2}=.20\right)$, medium in Study $4\left(\eta^{2}=.05\right)$, and large in Study $5\left(\eta^{2}=\right.$ .14), according to Fritz, Morris, and Richler (2012). We do not intend to question the methodology of any perceived corruption measurements; rather, we argue that perceived corruption may not reflect real corruption levels accurately because it is partly influenced by visible pollution.

Our findings suggest that physical environment could be one of the factors that drive errors in assessing society. Previous researches have demonstrated the errors in perceiving the levels of social class mobility (Chambers, Swan, \& Heesacker, 2015; Kraus, 2015; Kraus \& Tan, 2015) and official corruption (Abramo, 2008; Olken, 2009). Embodied cognition posits that people represent abstract concepts using physical perceptions such those of brightness and colour (Barsalou, 2008). If the physical environment activates these physical perceptions, the related abstract concepts (e.g., social perception) are also activated.

These findings also advance our understanding of embodied cognition by investigating a moderator, body consciousness. In Study 4, the link between haze and corrup- tion perception was limited to those who are most likely to attend to their own visceral reactions. This moderated effect suggested that individual awareness of visceral reactions might contribute to embody cognition.

It remains unknown whether the clear sky effect is universal or culturally specific. On the one hand, Study 2 found a relationship between haze and corruption perception across countries. Although the results of Study 2 were purely correlational, it suggests that the relationship between haze and perceived corruption is universal. On the other hand, previous research has demonstrated the cultural variability of embodiment (Lee \& Schwarz, 2012). Studies 3 and 4 were conducted in China. Further, the effect of haze on corruption perception is consistent with Chinese folklore. In Chinese culture, clear sky (青天) is used metaphorically to indicate political transparency. For example, Bao Zheng (999-1062), a government official known for his probity and integrity during the reign of Emperor Renzong in China's Song Dynasty, acquired the nickname 'Clear Sky Bao'. In the contemporary period, Clear Sky Bao (包青天) has become the hero of numerous TV series, video games, comic books, and crime fiction in the Chinese-speaking world (Hegel, 2010; Svensson, 2005). Similarly, Master of Clear Sky (青天大老爷) refers to the justice and integrity official in Chinese folklore. If the effect of haze on perceived corruption requires the availability of Chinese folklore, then the clear sky effect would be more pronounced in the Chinese-speaking world.

Some limitations of the present research must be pointed out. First, the aspect of the physical environment used in our studies was relatively subtle. Environmental pollution is a many-faceted phenomenon, and it is hard to explore the effects of all subtypes of environmental dirtiness on corruption perception. Would a dirty 
polluted stream, or some other form of dirtiness, increase corruption perception? Second, the operationalisation of pollution might be one way to strengthen the case for embodied cognition, relying on the metaphorical link between physical purity leading to moral purity. Third, in Study 4, we dichotomised the air quality index because it did not meet the statistical requirement for a continuous variable. We must admit that dichotomising this continuous variable discards information. Fourth, in this research, limited attention was given to corruption intention and behaviour. Bai, Liu, and Kou (2014) demonstrated the link between belief in a just world and corruption perceptions: they found that corruption intentions can be decreased by belief in a just world (Bai et al., 2016). We found a link between haze and corruption perceptions. Along similar lines, could clean sky perceptions decrease corruption intention? Future research may benefit from exploring these questions.

Regardless of all these limitations, our findings could have practical, important policy implications for governments struggling with high perceived corruption and environmental problems. Our findings show the political value of air quality. As Treisman (2000) stated, regardless of the accuracy of perceived corruption, it could exert consequences as serious as the corruption itself. For example, corruption perception erodes institutional trust (Chang \& Chu, 2006; Morris \& Klesner, 2010). The current results imply that politicians need to pay attention to environmental problems if they want to increase in the public's trust in them.

\section{Acknowledgments}

The authors would like to thank Professor James Liu and the anonymous reviewers for their constructive comments on the earlier versions of the paper. The authors gratefully acknowledge the financial support provided by Beijing Social Science Foundation (13ZHB027), the Program of the Co-Construction with Beijing Municipal Commission of Education of China, and the National Natural Science Foundation of China (31571145).

\section{References}

Abramo, C.W. (2008). How much do perceptions of corruption really tell us? Economics: The Open-Access, Open-Assessment E-Journal, 2. http://dx.doi.org/10.5018/ economics-ejournal.ja.2008-5013.

Aguilera, R., \& Vadera, A. (2008). The dark side of authority: Antecedents, mechanisms, and outcomes of organizational corruption. Journal of Business Ethics, 77, 431-449.

Arndt, C., \& Oman, C. (2006). Uses and abuses of governance indicators. Paris: Development Centre of the OECD.

Ata, A.Y., \& Arvas, M.A. (2011). Determinants of economic corruption: A cross-country data analysis. International Journal of Business and Social Science, 2, 161-169.
Böhm, G. (2003). Emotional reactions to environmental risks: Consequentialist versus ethical evaluation. Journal of Environmental Psychology, 23, 199-212.

Bai, B.-y., Liu, X.-x., \& Kou, Y. (2014). Belief in a just world lowers perceived intention of corruption: The mediating role of perceived punishment. PLoS ONE, 9, e97075.

Bai, B.Y., Liu, X.X., \& Kou, Y. (2016). Belief in a just world lowers bribery intention. Asian Journal of Social Psychology, 19, 66-75.

Barker, M.L. (1976). Planning for environmental indices: Observer appraisals of air quality. In K.H. Craik \& G.H. Zube (Eds.), Perceiving environmental quality (pp. 175-203). New York: Plenum Press.

Baron, R.M., \& Kenny, D.A. (1986). The moderator-mediator variable distinction in social psychological research: Conceptual, strategic, and statistical considerations. Journal of Personality and Social Psychology, 51, 1173-1182.

Barsalou, L.W. (2008). Grounded cognition. Annual Review of Psychology, 59, 617-645.

Beck, A.T., Epstein, N., Brown, G., \& Steer, R.A. (1988). An inventory for measuring clinical anxiety: Psychometric properties. Journal of Consulting and Clinical Psychology, 56, 893897.

Bickerstaff, K., \& Gordon, W. (2001). Public understandings of air pollution: The 'localisation' of environmental risk. Global Environmental Change, 11, 133-145.

Brauer, M., Hoek, G., Smit, H.A., de Jongste, J.C., Gerritsen, J., Postma, D.S., .. Brunekreef, B. (2007). Air pollution and development of asthma, allergy and infections in a birth cohort. European Respiratory Journal, 29, 879-888.

Č́belková, I., \& Hanousek, J. (2004). The power of negative thinking: Corruption, perception and willingness to bribe in Ukraine. Applied Economics, 36, 383-397.

Chambers, J.R., Swan, L.K., \& Heesacker, M. (2015). Perceptions of U.S. social mobility are divided (and distorted) along ideological lines. Psychological Science, 26, 413-423.

Chang, E.C.C., \& Chu, Y.-H. (2006). Corruption and trust: Exceptionalism in Asian democracies? Journal of Politics, 68, 259-271.

Charron, N. (2015). Do corruption measures have a perception problem? Assessing the relationship between experiences and perceptions of corruption among citizens and experts. European Political Science Review. Advance online publication.

Cole, M.A. (2007). Corruption, income and the environment: An empirical analysis. Ecological Economics, 62, 637647.

Craig, S., Niemi, R., \& Silver, G. (1990). Political efficacy and trust: A report on the NES pilot study items. Political Behavior, 12, 289-314.

Damania, R., Fredriksson, P.G., \& John, A.L. (2003). Trade liberalization, corruption, and environmental policy formation: Theory and evidence. Journal of Environmental Economics and Management, 46, 490-512.

Davis, J.H., \& Ruhe, J.A. (2003). Perceptions of country corruption: Antecedents and outcomes. Journal of Business Ethics, 43, 275-288. 
Dockery, D.W., \& Pope, C.A. (1994). Acute respiratory effects of particulate air pollution. Annual Review of Public Health, 15, 107-132.

Dong, B., Dulleck, U., \& Torgler, B. (2012). Conditional corruption. Journal of Economic Psychology, 33, 609-627.

Fisman, R., \& Gatti, R. (2002). Decentralization and corruption: Evidence across countries. Journal of Public Economics, 83, 325-345.

Fritz, C.O., Morris, P.E., \& Richler, J.J. (2012). Effect size estimates: Current use, calculations, and interpretation. Journal of Experimental Psychology: General, 141, 2-18.

Giessner, S.R., \& Schubert, T.W. (2007). High in the hierarchy: How vertical location and judgments of leaders' power are interrelated. Organizational Behavior and Human Decision Processes, 104, 30-44.

Hegel, R.E. (2010). Judge Bao and the rule of law: Eight ballad stories from the period 1250-1450. China Review International 17, 240-244.

Huang, J.L. (2014). Does cleanliness influence moral judgments? Response effort moderates the effect of cleanliness priming on moral judgments. Frontiers in Psychology, 5, 1276.

Hyslop, N.P. (2009). Impaired visibility: The air pollution people see. Atmospheric Environment, 43, 182-195.

Johansson, M., Pedersen, E., Maleetipwan-Mattsson, P., Kuhn, L., \& Laike, T. (2014). Perceived outdoor lighting quality (POLQ): A lighting assessment tool. Journal of Environmental Psychology, 39, 14-21.

Kraus, M.W. (2015). Americans still overestimate social class mobility: A pre-registered self-replication. Frontiers in Psychology, 6, 1709.

Kraus, M.W., \& Tan, J.J.X. (2015). Americans overestimate social class mobility. Journal of Experimental Social Psychology, 58, 101-111.

Landau, M.J., Meier, B.P., \& Keefer, L.A. (2010). A metaphorenriched social cognition. Psychological Bulletin, 136, 10451067.

Lee, S.W.S., \& Schwarz, N. (2010). Dirty hands and dirty mouths: Embodiment of the moral-purity metaphor is specific to the motor modality involved in moral transgression. Psychological Science, 21, 1423-1425.

Lee, S.W.S., \& Schwarz, N. (2011). Wiping the slate clean: Psychological consequences of physical cleansing. Current Directions in Psychological Science, 20, 307-311.

Lee, S.W.S., \& Schwarz, N. (2012). Bidirectionality, mediation, and moderation of metaphorical effects: The embodiment of social suspicion and fishy smells. Journal of Personality and Social Psychology, 103, 737-749.

Lessmann, C., \& Markwardt, G. (2010). One size fits all? Decentralization, corruption, and the monitoring of bureaucrats. World Development, 38, 631-646.

MacKinnon, D. P., Fairchild, A. J., \& Fritz, M. S. (2007). Mediation analysis. Annual Review of Psychology, 58(1), 593-614.

Mazar, N., \& Aggarwal, P. (2011). Greasing the palm: Can collectivism promote bribery? Psychological Science, 22, 843-848.
McCann, J., \& Holt, R. (2009). Ethical leadership and organizations: An analysis of leadership in the manufacturing industry based on the Perceived Leadership Integrity Scale. Journal of Business Ethics, 87, 211-220.

Meier, B.P., Robinson, M.D., \& Clore, G.L. (2004). Why good guys wear white: Automatic inferences about stimulus valence based on brightness. Psychological Science, 15, 82-87.

Miller, L.C., Murphy, R., \& Buss, A.H. (1981). Consciousness of body: Private and public. Journal of Personality and Social Psychology, 41, 397-406.

Morris, S.D., \& Klesner, J.L. (2010). Corruption and trust: Theoretical considerations and evidence from Mexico. Comparative Political Studies, 43, 1258-1285.

Niedenthal, P.M., Barsalou, L.W., Winkielman, P., KrauthGruber, S., \& Ric, F. (2005). Embodiment in attitudes, social perception, and emotion. Personality and Social Psychology Review, 9, 184-211.

Nuijten, M. (2004). Between fear and fantasy: Governmentality and the working of power in Mexico. Critique of Anthropology, 24, 209-230.

Olken, B.A. (2009). Corruption perceptions vs. corruption reality. Journal of Public Economics, 93, 950-964.

Olson, D.V.A., \& Carroll, J.W. (1992). Religiously based politics: Religious elites and the public. Social Forces, 70, 765-786.

Risen, J.L., \& Critcher, C.R. (2011). Visceral fit: While in a visceral state, associated states of the world seem more likely. Journal of Personality and Social Psychology, 100, 777-793.

Ruch, W.A., \& Newstrom, J.W. (1975). How ethical are we? Supervisory Management, 16-21.

Schnall, S., Benton, J., \& Harvey, S. (2008). With a clean conscience: Cleanliness reduces the severity of moral judgments. Psychological Science, 19, 1219-1222.

Schnall, S., Haidt, J., Clore, G.L., \& Jordan, A.H. (2008). Disgust as embodied moral judgment. Personality and Social Psychology Bulletin, 34, 1096-1109.

Schwarz, N., \& Clore, G.L. (1983). Mood, misattribution, and judgments of well-being: Informative and directive functions of affective states. Journal of Personality and Social Psychology, $45,513-523$.

Schubert, T.W. (2005). Your highness: Vertical positions as perceptual symbols of power. Journal of Personality and Social Psychology, 89, 1-21.

Seleim, A., \& Bontis, N. (2009). The relationship between culture and corruption: A cross-national study. Journal of Intellectual Capital, 10, 165-184.

Sherman, G.D., \& Clore, G.L. (2009). The color of sin: White and back are perceptual symbols of moral purity and pollution. Psychological Science, 20, 1019-1025.

Snijders, T.A.B., \& Bosker, R.J. (1999). Multilevel analysis: An introduction to basic and advanced multilevel modelling. London: Sage.

Song, X., \& Cheng, W. (2012). Perception of corruption in 36 major Chinese cities: Based on survey of 1,642 experts. Social Indicators Research, 109, 211-221. 
Svensson, M. (2005). The media as the judge: the role of the Chinese media in addressing injustices. Asia Insights, 3, 1517.

Tan, X., Liu, L., Huang, Z., Zhao, X., \& Zheng, W. (2016). The dampening effect of social dominance orientation on awareness of corruption: Moral outrage as a mediator. Social Indicators Research, 125, 89-102.

Transparency International. (2013). Corruption Perception Index. Retrieved from http://www.transparency.org/ cpi2012/in_detail/

Treisman, D. (2000). The causes of corruption: A crossnational study. Journal of Public Economics, 76, 399457.
U.S. Environmental Protection Agency. (2014). Air quality index (AQI) - A guide to air quality and your health. Retrieved from http://airnow.gov/index.cfm?action=aqibasics.aqi

Welsch, H. (2004). Corruption, growth, and the environment: A cross-country analysis. Environment and Development Economics, 9 663-693.

Zanolie, K., Dantzig, S. v., Boot, I., Wijnen, J., Schubert, T.W., Giessner, S.R., \& Pecher, D. (2012). Mighty metaphors: Behavioral and ERP evidence that power shifts attention on a vertical dimension. Brain and Cognition, 78, 50-58.

Zhong, C.-B., \& Liljenquist, K. (2006). Washing away your sins: Threatened morality and physical cleansing. Science, 313, 1451-1452. 